\title{
Anniversary Meeting of the Royal Society
}

\begin{abstract}
FTER reference, according to "pious custom", to the work of the two foreign members and fourteen fellows of the Royal Society who died during the past twelve months, Sir Frederick Gowland Hopkins, in his anniversary meeting address on November 30 as president of the Society, made a plea for the establishment of chairs in the history of science. Individual scientific achievement is stored in fewer memories than is great literature, partly because it is but a step in the progress of knowledge. The perspective of history is specially valuable in maintaining sound judgments in these days of revolutionary views. Christopher Wren provides an example of a man whose services for experimental science have been overshadowed, except for the few, by other achievements. The tercentenary of his birth occurred during the past year, and also that of Antony van Leeuwenhoek and of Marcello Malpighi, both of whom were also associated with the Royal Society during its early years. The number of tercentenaries of original and early fellows of the Society falling during a small span of years makes it impossible to organise a public celebration of each such event.
\end{abstract}

Sir Frederick stated that the Society is to receive an important benefaction for the support of qualified investigators. Shortly before his death, Mr. Gordon Warren allocated to the Society the sum of $£ 1,400$ a year for seven years for the maintenance of a research professorship or two research fellowships. Two Warren research fellows, Dr. A. J. Bradley and Dr. W. Hume-Rothery were accordingly appointed last June. Mr. Warren died suddenly, leaving a large sum of money, subject to a life interest, which is ultimately to be devoted to science, and the Royal Society is to be consulted as to its disposal.

The Royal Soeiety Mond Laboratory at Cambridge (NATURE, Feb. 13, 1932, p. 224) is practically complete and will be opened in February.

We print below extracts from the president's remarks in bestowing this year's medals.

\section{Presentation of Medals}

Copley Medal, awarded to Dr. G. E. Hale

Dr. Hale's first notable achievement was in 1892, when he brought the spectroheliograph to success. This instrument gives a picture of the sun by the light of one spectrum line, and allows the bright clouds of hydrogen and calcium in the upper regions of the sun's atmosphere to be photographed as projected on the disc. The idea had been suggested and tried much earlier, but Hale was the first to make a workable automatic instrument of this kind. About the year 1895 Hale organised the building of the Yerkes Observatory and of the great refracting telescope there, to which an improved spectroheliograph was adapted. To this period belongs also a masterly investigation of the spectra of certain faint red stars. This was the precursor of a much larger enterprise, the Mount Wilson Observatory, with many unique instruments, such as the $150 \mathrm{ft}$. tower telescope and the 100 in. diameter reflector.

At the Mount Wilson observatory Dr. Hale made his great discovery of the Zeeman effect in sunspots by observing the circular polarisation of the edges of the broadened spectrum lines, where they cross the spot. Regions of thousands of miles across were thus shown to be the seat of intense magnetic forces, comparable in strength with those used in the dynamo machine. This discovery has been developed in many important directions.

In recent.years Dr. Hale has developed the spectrohelioscope, an instrument depending on the persistence of vision, which allows us to observe transient phenomena scarcely accessible to the spectro. heliograph. We may confidently expect that it will contribute to clearing up the mysterious relations between terrestrial magnetism and solar phenomena.

\section{Rumford MedaI, awarded to Prof. Fritz Haber}

Alike at Karlsruhe, where he went in 1894 , and at Dahlen from 1911 to the present time, Haber has inspired schools of great and highly productive activity. His own early studies of the oxidation and reduction of organic substances by electrochemical methods, and the numerous electrochemical studies which followed this important work, such as his researches on gas cells, on the rate of ionic reactions, on the electrolysis of solid salts, on the velocity of reaction at electrodes, and on the use of the glass electrode, have enormously advanced progress in this branch of science.

Haber's profound study of the thermodynamics of gas reactions culminated the synthetic production of ammonia. With van Oort, he carried out a preliminary investigation on the ammonia equilibrium, but owing partly to discrepancy with figures obtained by application of the Nernst theorem, further experiments were made with le Rossignol in 1906. In 1908 satisfactory eatalysts had been found and the synthesis of ammonia achieved. The far-reaching technical results of these careful thermodynamical studies are in themselves a monument to Fritz Haber ; one of the German factories alone can produce more than 1,000 tons of ammonia daily. The influence of this on the food supply of the world is of the highest importance.

Haber's wide interest, combined with his insight and grasp, made possible the application of modern physical principles to a wide range of problems of physical chemistry, such as the determination of molecular structure and calculation of lattice energies, the nature of the amorphous state, chemiluminescence, reaction kinetics and electron emission during chemical reaction. During the past few years, Haber has been successfully making manifest the rôle of the hydrogen atom in combustion processes.

\section{Royal Medal, awarded to Prow. R. Robinson}

Prof. Robert Robinson has won world-wide distinction by his work in many branches of organic chemistry, particularly by his elucidation of the structure of plant products and of their phytochemical synthesis. No living organic chemist has displayed a greater versatility of thought and of method. His more recent researches on the distribution, the constitution and the laboratory synthesis of the anthocyanins, the pigments of flowers, fruits and berries, have excited the keenest interest of chemists and biologists. His work on the structure of alkaloids and the syntheses to which it has led

No. 3293, VoL. 130] 
him are classical in character. The synthesis of tropinone has been referred to as the most elegant in chemical literature. On the mechanism of chemical reaction he has contributed theoretical ideas which, of interest both to chemists and physicists, have opened new avenues of investigation.

\section{Royal Medal, awarded to Prof. E. Merlanby}

Prof. Edward Mellanby showed that the central factor in the development of rickets is a defective diet. He introduced experimental methods, produced pickets by feeding animals on a deficient diet, and showed that the missing factor was of the nature of a fat-soluble vitamin. Previously only clinical observations had been recorded, on the effect of sunlight, and on other supposed factors; there was no sound evidence that a material substance regulates the calcification of bone. It was Mellanby's fundamental work which during the last decade made possible numerous and important researches by others, culminating a year ago in the recognition of the material substance (vitamin D) as an isomeride of ergosterol.

Mellanby's later researches suggest hitherto unsuspected problems, though their very novelty has so far precluded the clear definition and finality which is now the outcome of his earlier works. Thus he has shown the adverse effect, in certain circumstances, of an excessive amount of cereal germs. In the absence of vitamin $\mathbf{A}$ the latter, and particularly ergot of rye, produce a degeneration of the spinal cord. Incidentally, this observation provides a satisfactory explanation of the peculiar and hitherto obscure incidence of convulsive ergotism in man.

\section{Davy Medal, awarded to Prof. R. Winlstätter}

Prof. Willstätter's earlier studies gave us our present complete knowledge of the molecular structure of atropine and cocaine, and his analytic and synthetic studies of these alkaloids have had important sequels in systematic organic chemistry and in pharmacology. He then proceeded to a series of ingenious researches bearing on the problem of quinonoid character and on the benzene theory and these led in succeeding years to further work on cyclic compounds of much general interest. He early showed himself to be a master of method in organic chemistry. His name will, in the future, bring most readily to mind the discovery of magnesium in chlorophyll, and this, along with the painstaking and monumental investigations of the structure of chlorophyll and the blood pigment, represents the high-water mark of his achievement. Coupled with this work was a series of valuable contributions to the study of carbon assimilation. Equally novel and brilliant were his researches on the anthocyanin pigments of flowers and blossoms; a whole now chapter of organic chemistry was written. Finally, the studies on the enzymes have added greatly to our positive knowledge, enabled us fully to estimate the difficulty of the task, and laid down the lines on which future work must proceed.

Darwin Medal, awarded to Dr. C. E. Correns

Dr. Correns was one of the three botanists (the other two being Tschermak and de Vries) who in 1900 independently brought to the notice of biologists the fundamental work of Mendel, which had remained neglected since 1865. Since 1900 he has been actively engaged in developing the science of genetics.
In 1902 Correns was the first to elucidate the remarkable phenomenon of the production of red flowers in the first cross between two white-flowered races of Mirabilis. He was also the first to show in the crossing of two species of Mirabilis that if very numerous genetic factors relating to small morphological differences are present, it is impossible to establish segregation in the $F_{2}$ generation, unless very large numbers are available. This explains the appearance of supposed 'constant' hybrids, as has since been shown by other observers in numerous instances.

Correns was also the first experimenter clearly to establish inheritance which did not follow Mendelian rules. Thus he showed in Mirabitis and other plants that variegation of the leaves depending on the failure to develop chlorophyll, is inherited only through the mother because the plastids which carry the chlorophyll are present in the egg cell and not in the sperm. Again, he demonstrated that paternal characters shown by extra-embryonal parts of fruits produced by crossing (so-called 'xenia') were always limited to the endosperm, that is, to the food tissue formed by the fusion of a second sperm with nuclei belonging to the maternal parent. But his most important work is probably the elucidation of the inheritance of sex. By crossing a monœeious with a diœcious species of Bryonia, he showed in 1907 that the females were all homozygous and the males heterozygous for the sex factor. The generalisation that one sex is always homozygous and the other heterozygous corresponds with the normal approximately equal distribution of the sexes in the offspring of unisexual individuals and with the differences between the chromosomes of the sexcells, and is now well-established. Deviation from the equal distribution of the sexes Correns showed to be due in Melandrium to the more rapid action of the male-determining sperms, and this is a principle of wide application. Again, he was the first to explain the differential fertility of a generation of plants with their parents and with one another by the assumption of two distinct and inherited inhibiting substances in the stigmata of the flowers.

Buchanan Medal, awarded to Prof. T. Madsen

Dr. Madsen's best known scientific work has been on the toxins and anti-toxins of diphtheria and tetanus bacilli and on other animal, vegetable and bacterial toxins and antigens and their antibodies. He initiated and published with Arrhenius, classical work on the theory of toxin and antitoxin combination, showing that the process resembled the com. bination of a weak acid and base rather than the union of a strong acid and base, as had been held by Ehrlich.

Madsen was largely concerned with the origin of the Commission on Hygiene, which he directed in Eastern Europe during the latter part of the War. Since then he has been president of the Health Committee of the League of Nations and president of the Permanent International Committee on Biological Standards, which was in great part due to his initiative.

Hughes Medal, awarded to Dr. J. Chadwick

Dr. Chadwick is distinguished for his contributions to radioactivity and nuclear physics. Amongst a number of other investigations on $\alpha-, \beta$ - and $\gamma$-rays, he was the first to show explicitly about 1920 that the charge on the nucleus was equal to the atomic

No. 3293, Vol. 130] 
number, by a quantitative study of the large-angle scattering of $\alpha$-particles by selected elements, thus verifying by direct experiment the correctness of Moseley's deduction. He was associated with Rutherford, 1922-30, in a long series of investigations (1) on the anomalous scattering of $\alpha$-particles by light elements, which threw the first light on the size and structure of the nucleus, and (2) on the artificial transmutation of the elements by $\alpha$-ray bombardment. These experiments showed that at least twelve of the lighter elements were transmuted with the ejection of a proton, and laid the found. ations of a study which has recently so rapidly accelerated.

In 1928 efforts were started to improve the technique of these experiments by using automatic electrical counting, and methods were perfected by the end of 1930. Dr. Chadwick applied the new methods to a more detailed study of the groups of disintegration protons, especially from boron and aluminium, for which he established clearly for the first time the existence of definite nuclear $\alpha$-particle and proton levels. Finally this year, when the observations by M. and Mme. Curie-Joliot had indicated certain curiosities produced by the supposed $\gamma$-radiation from beryllium bombarded by $\alpha$-particles, Dr. Chadwick immediately recognised that the effects observed could only be adequately explained by the assumption that the radiation from beryllium was of a new type-the ejection of a neutron-and by a brilliant series of experiments he confirmed this conjecture, and with the collaboration of Dee and Feather was able to establish its essential properties.

\section{The Place of Biology in Education}

$\mathrm{T}^{\mathrm{s}}$ HE National Conference on the Place of Biology in Education, organised by the British Social Hygiene Council, which met at the British Medical Association House on November 1-December 3, may well prove a landmark in the history of education in Great Britain. When five Ministries, the chairmen of the Advisory Council to the Department of Scientific and Industrial Research, of the Medical Research Council, and of practically every educational body of importance, appear among the patrons, and when administrators and leaders of research such as Viscount Chelmsford, Sir Walter Fletcher, Sir Richard Gregory, Sir William Hardy, Prof. A. V. Hill, Sir Michael Sadler, Sir Amherst Selby-Bigge, and Sir Stephen Tallents appear side by side with men of high standing in the educational world, the public cannot dismiss their arguments as unimportant.

Since the purpose of the Conference was not to pass resolutions but to drive home the fact that competent judges in the spheres of national and imperial affairs, of research, of teaching, and of sociology are agreed upon the urgent necessity of providing the administrator, the social worker, and the ordinary citizen with a biological background, it would be difficult to imagine a gathering of greater weight, or one more likely to produce results.

Since it is hoped that a full report will shortly be available, it is as unnecessary as it would be impossible to attempt a detailed summary; but such an utterance of authoritative opinion certainly calls for a record of the general impression it left behind. The earlier speeches laid a firm foundation. Lord Chelmsford's account of the Prime Minister's committee over which he presided fittingly reminded those attending the Conference that they were deliberating matters of world-wide importance. Besides dealing with the specialist, the report of that committee emphasises the cultural value of biology, and states that no boy should leave school without some knowledge of it. Sir Michael Sadler, setting evolution against the background of the absolute, widened the horizon, and insisted that biological education demands a philosophy of life. Sir Walter Fletcher carried the theme further in a noble progression. Biology is essential in a mechanical age because it answers the human needs of utility, beauty, and worship. By putting utility lowest and then proceeding to show how neglect of biological research has lost us the sugar trade of the world, destroyed the trade in vegetable dyes, and brought us up against social problems even more anxious, while English wheat-growing has been saved by such research, he gave fitting emphasis to the higher needs. Prof. A. V. Hill laid stress on the fact that all science is one, and urged that since civilisation expresses the activity of a living organism, man, biological knowledge is essential to its understanding. Then speaker after speaker, from many-sided experience, while emphasising the danger of such specialisation as has overtaken chemistry and physics, impressed the truth that to be totally ignorant of biology is to be an incompetent citizen and a dangerous legislator.

More and more clearly emerged the demand for two kinds of biological training. The specialist is required for many purposes and the need is a growing one despite the economic set-back which has temporarily narrowed or closed some avenues; though if the specialist is not thoroughly trained in chemistry and physics his usefulness is greatly restricted. But unless every single citizen is educated in the understanding of biological ideas, then problems of industry, economics, population, and the mentally unfit, may prove too much for us. On every side the biological aspects of citizenship grow more significant and the need for biological education more urgent.

The fundamental note of the Conference was the recognition of this need, and of the corollary that in every stage of education, and for girls as well as for boys, biology must have its place. In the primary schools there has been little progress. Here Sir Richard Gregory wisely stressed the need of natural interest rather than of the illustration of scientific laws in the early stages. Other speakers showed how eagerly young children respond to teaching about the living organism.

The situation in teachers' training colleges, in central and secondary schools, in preparatory and public schools came under review, and the cry for more and better biology, biology on broader lines, was everywhere the same. Not least significant was the complaint of the headmaster of a preparatory school that there would be time for natural history if many parents did not so neglect early education that their sons reached the preparatory school unable to write grammatically or to do simple arithmetic. Nevertheless, it became clear that, in the opinion of the Conference, the preparatory schools could do an immense amount for the public schools by

No. 3293, Vol. 130] 